\title{
A case of thyroid anaplastic carcinoma presenting marked neutrophilia and eosinophilia due to co- production of gm-CSF, m-CSF and il-6
}

\begin{abstract}
Thyroid anaplastic carcinoma is an extremely aggressive neoplasm. Even in the recent reports, the prognosis of anaplastic thyroid carcinoma has been unhopeful, and the median survival is limited to months. We experienced a case of thyroid anaplastic carcinoma which exhibited a marked increase in the number of white blood cells (neutrophils, eosinophils and monocytes) and the elevation of serum levels of GMCSF, M-CSF and IL-6.
\end{abstract}

Keywords: thyroid anaplastic carcinoma, tumor-related leukocytosis, colonystimulating factors

\author{
Volume 3 Issue 2 - 2017 \\ Jun-Ichi Saitoh, Katsuyukii Shirai, Atsushi \\ Musha, Tatsuji Mizukami, Takanori Abe, \\ Takashi Nakano \\ Department of Radiation Oncology, Gunma University \\ Graduate School of Medicine, Japan
}

\begin{abstract}
Correspondence: Jun-ichi Saitoh, Department of Radiation Oncology, Gunma University Graduate School of Medicine, 3-39-22 Showa-machi, Maebashi, Gunma 37I-85II, Japan, Tel +81272208383 , Fax +8I272208397,

Email junsaito@gunma-u.ac.jp
\end{abstract}

Received: May 21, 2017 | Published: June 15, 2017

\begin{abstract}
Abbreviations: CSF, colony-stimulating factor; G-CSF, granulocyte-macrophage-colony stimulating factor; GM-CSF, granulocyte-macrophage-colony stimulating factor; M-CSF, macrophage-colony stimulating factor; IL-6, interleukin-6; WBC, white blood cell
\end{abstract}

\section{Introduction}

Increased levels of white blood cells in cancer patients are sometimes noticed. These are caused by coexisting infectious disease for the most part. Tumor-related leukocytosis without infection is seen in some cases. Recently, it has been known that the tumor cells themselves occasionally produce colony-stimulating factors (CSF) such as granulocyte-colony stimulating factor (G-CSF), granulocytemacrophage-colony stimulating factor (GM-CSF), macrophagecolony stimulating factor (M-CSF) and bring on marked leukocytosis, but the incidence and mechanism of leukocytosis caused by malignant neoplasms are still unclear. Asano et al. reported G-CSF producing lung carcinoma in 1977, ${ }^{1}$ and CSF-producing carcinomas have been reported arised from various site, such as lung, pancreas, bladder, kidney, uterus, stomach, gall bladder, esophagus, soft tissue, oral cavity, brain, and so on. Relatively high incidence of tumor-related leukocytosis is seen in lung cancer patients. Kasuga et al. ${ }^{2}$ reported 33 cases revealed tumor-related leukocytosis in 227 lung cancer patients $(14.5 \%)$ and 29 of 33 cases showed high serum levels of either G-CSF, GM-CSF, or interleukin-6 (IL-6). ${ }^{2}$ However, in thyroid cancer patients, there are a few reports about tumor-related leukocytosis which were accompanied by the production of CSF. And there are extremely rare case those represented the co-elevation of the serum levels of GM-CSF and M-CSF.

We report a case of thyroid anaplastic carcinoma which exhibited a marked increase in the number of white blood cells (neutrophils, eosinophils and monocytes) and the elevation of serum levels of GM-CSF, M-CSF and IL-6.

\section{Case presentation}

A 73year old male was admitted to our hospital because of hoarseness and a right neck nodule. From a month prior to admission, he suffered from cough and sputum, and consulted to another doctor first. He was pointed out the tumor in the right lobe of thyroid gland and the deviation of trachea on chest X-ray and CT scan of the neck and upper mediastinum (Figure 1), and he referred to our hospital for further investigation and treatment.

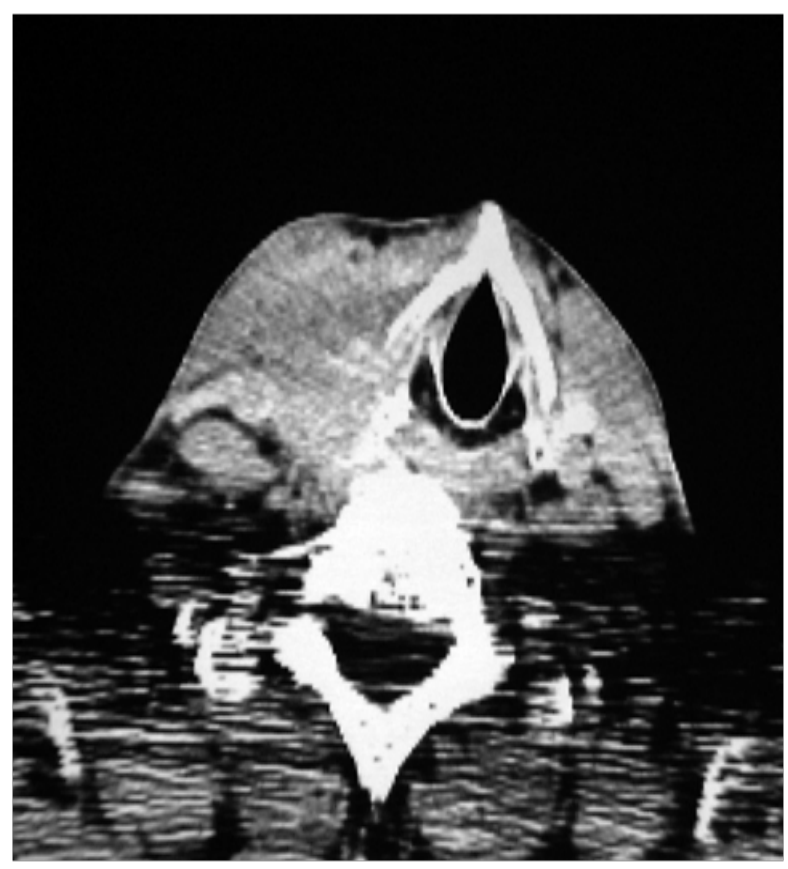

Figure I CT image of thyroid tumor before treatment. 
In his family history, his father died of esophageal carcinoma when he was 77years old. In the past history, he came up with pleuritis when he was a student, and he got pneumonia 21years ago. On admission, an elastic hard tumor of about $40 \mathrm{~mm}$ in diameter was noted in the right supraclavicular region, and right cervical and supraclavicular lymph nodes were palpable. Redness of skin was not observed. General condition was relatively good. On physical examination, no rales could be heard in the bilateral lung fields. Ultrasound imaging showed high echogenic solid nodules in the right lobe of the thyroid gland. The next day after admission, CT scan was performed again for re-evaluation. The cervical CT revealed a heterogeneous low density mass lesion in the right lobe of the thyroid gland and the tracheal shift to the left. The chest CT showed multiple nodules in bilateral lung fields, which were not recognized in the first CT scan three weeks ago. Aspiration biopsy of the thyroid tumor was performed, and the diagnosis of class $\mathrm{V}$, anaplastic carcinoma was made cytologically (Figure 2). Laboratory investigations on admission was summarized in Table 1A. Total white blood cell (WBC) count was $9800 / \mu 1$, and the counts of neutrophils, eosinophils, monocytes were $6760 / \mu 1(69 \%)$, $1130 / \mu 1(12 \%), 680(7 \%)$, respectively. C-reactive protein was $0.2 \mathrm{mg} /$ dl. Serum thyrogloblin was markedly elevated, the numeric value of which was $12555 \mathrm{ng} / \mathrm{ml}$.

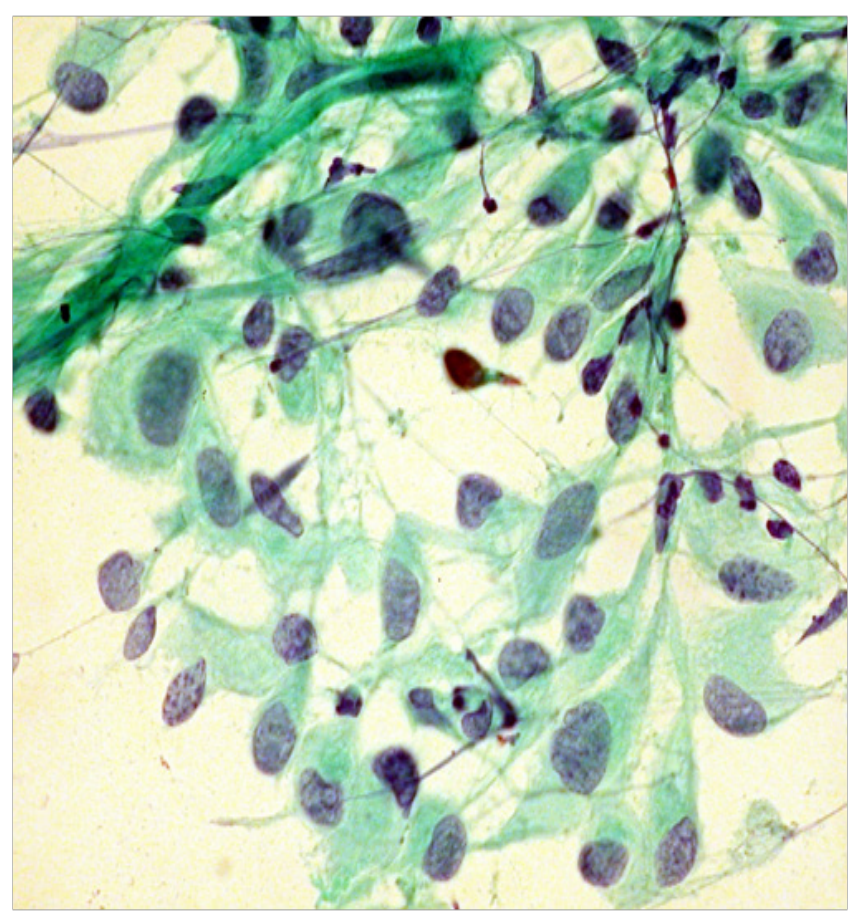

Figure $2 \mathrm{~A}$ cytologic specimen of aspiration biopsy from thyroid tumor.

As to the treatment, there was no indication of radical surgical treatment, because of local tumor invasion, metastatic lung nodules and histological finding. Radiation therapy was performed using $10 \mathrm{MV}$ X-ray, anteroposterior opposed fields for prevention of airway narrowing. The treatment was performed with accerelated hyperfractionation schedule (1.6Gy per fraction, twice daily). At first, the tumor increased in volume in spite of the treatment, but it decreased gradually. However, multiple lung metastases developed extremely rapid. Because a marked elevation of thyroglobulin was observed on laboratory finding, we anticipated that the tumor cells had the characteristic of well differentiated thyroid carcinoma. So the treatment by internal use of ${ }^{131} \mathrm{I}(1.85 \mathrm{GBq})$ was performed for the control of metastatic tumors. However, whole body scintigraphy showed accumulation of ${ }^{131} \mathrm{I}$ only in the thyroid gland and accumulations in the metastatic lesions were not distinct. A month after the start of treatment, gradual increase in total WBC count was observed without inflammatory reaction. WBC count exceeded $30000 / \mu 1$, and the growing fractions were neutrophils, eosinophils and monocytes (Figure 3). Antibiotic therapy was performed, but number of peripheral white blood cells increased moreover according to tumor progression. Considering the possibility of tumor-related leukocytosis, the serum CSF levels was examined. Serum G-CSF level was within normal limit. On the other hand, serum GM-CSF was elevated, the value of which was $89 \mathrm{pg} / \mathrm{ml}$ (normal value $<2 \mathrm{pg} /$ $\mathrm{ml}$ ). In a month later, we additionally examined serum levels of other cytokines and CSF. The results of examination were shown in Table 1B. Second measurement of serum GM-CSF value showed 749pg/ $\mathrm{ml}$. Serum levels of M-CSF and IL-6 also elevated, the values were $1950 \mathrm{pg} / \mathrm{ml}$ (normal value $<515 \mathrm{pg} / \mathrm{ml}), 68.8 \mathrm{pg} / \mathrm{ml}$ (normal value $<4.0 \mathrm{pg} /$ $\mathrm{ml}$ ), respectively. Two months after the start of treatment, multiple huge nodules with interstitial shadows could be seen in his chest radiographs, and the patient died of respiratory failure.

Autopsy was performed. Yellow multinodular mass was seen in the right lobe of the thyroid gland. Uncounted numbers of metastatic nodules were seen in bilateral lungs. One of the largest nodules had the necrotic cavity. Metastases were also found in liver, kidney, stomach, small intestine, colon, mesenterium, and left adrenal gland. In the microscopic findings, tumor cells were large and spindle-shaped. Multinucleated giant cells were observed in the tumor. Partially, component of well differentiated papillary carcinoma could be seen in thyroid tumor. Infiltration of neutrophils were also found in thyroid mass.

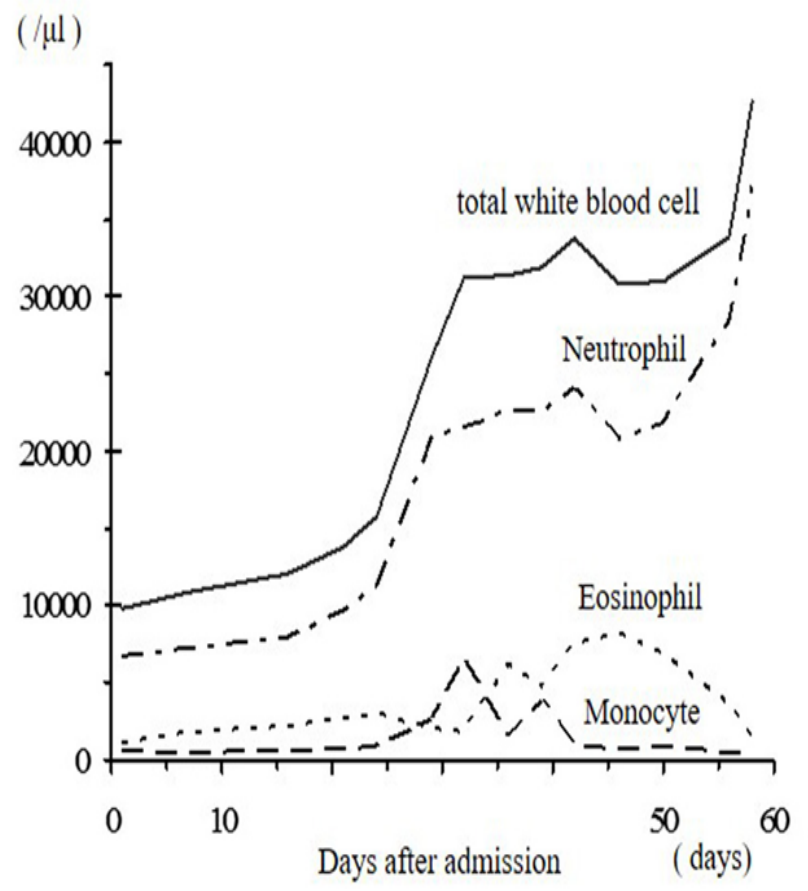

Figure 3 A transition of counts of white blood cells. 
Table I Laboratory test values

\begin{tabular}{|c|c|c|}
\hline Table IA & & Table IB \\
\hline Peripheral blood & BUN(I2mg/dl) & Colony stimulating factors \\
\hline White blood cells $(9800 / \mu l)$ & Creatinine $(0.8 \mathrm{mg} / \mathrm{dl})$ & G-CSF(24.2pg/ml) \\
\hline Neutrophil(69\%) & Uric $\operatorname{acid}(4.2 \mathrm{mg} / \mathrm{dl})$ & GM-CSF(749pg/ml) \\
\hline Eosinophil(12\%) & Sodium(I4ImEq/l) & M-CSF(1950pg/ml) \\
\hline Basophil(0\%) & Potassium(4.3mEq/l) & Cytokines \\
\hline Monocyte(7\%) & Chloride(I08mEq/I) & IL-3(<8pg/ml) \\
\hline Lymphocyte(I2\%) & Calcium(8.4mg/dl) & $\mathrm{IL}-5(<\mathrm{I} 5 \mathrm{pg} / \mathrm{ml})$ \\
\hline Red blood cells $\left(44 \mid \times 10^{4} / \mu \mathrm{l}\right)$ & Inorganic phosphate(3.5mg/dl) & IL-6(68.8pg/ml) \\
\hline Hemoglobin( $(2.9 \mathrm{~g} / \mathrm{dl})$ & Serology & \\
\hline Hematocrit(38.9\%) & $\operatorname{CRP}(0.2 \mathrm{mg} / \mathrm{dl})$ & 40 days after admission \\
\hline Platelets $\left(22 . \mid \times 10^{4} / \mu \mathrm{l}\right)$ & Blood sugar(87mg/dl) & White blood cells $(31900 / \mu \mathrm{l})$ \\
\hline Blood chemistry & Thyroid function & Neutrophil(7I\%) \\
\hline Total protein $(6.5 \mathrm{~g} / \mathrm{dl})$ & Triiodothyronin(I.73ng/ml) & Eosinophil(I5\%) \\
\hline Albumin $(3.5 \mathrm{~g} / \mathrm{dl})$ & Thyroxine( $8.1 \mu g / d l)$ & Monocyte(I2\%) \\
\hline Total bilirubin( $0.7 \mathrm{mg} / \mathrm{dl})$ & Thyroid stimulating hormone & \\
\hline AST I I(IU/I) & $0.97 \mu \mathrm{lU} / \mathrm{ml}$ & \\
\hline ALT 8(IU/I) & Tumor marker & \\
\hline LDH 390(IU/I) & Thyroglobulin(I2555ng/ml) & \\
\hline ALP I40(IU/I) & Calcitonin(I8pg/ml) & \\
\hline$\gamma$-GTP 4(IU/I) & $\mathrm{CEA}(<\mathrm{l} .0 \mathrm{ng} / \mathrm{ml})$ & \\
\hline
\end{tabular}

\section{Discussion}

Thyroid anaplastic carcinoma is an extremely aggressive neoplasm. The prognosis of anaplastic thyroid carcinoma has been unhopeful, and the median survival is limited to months. ${ }^{3}$ If surgical complete resection is possible, favorable outcome might be promising. ${ }^{3}$ But many patients who could be completely resected the anaplastic thyroid carcinoma were found their tumors incidentally. In 40-60\% of all cases, distant metastases were found on admission, and curative surgical resection was impossible in greater part of thyroid anaplastic cancer patients. In this patient, primary endpoint of treatment was to prevent the upper airway obstruction. Radiation therapy was performed with acceralated hyperfractionation schedule, and upper airway management was possible until his death. Metastatic lesions in the lung grew extremely rapid, compatible with the aggressive course of thyroid anaplastic carcinoma. Because manifest rise in serum thyroglobulin was seen in this patient, we expected that metastatic tumors in this patient have a character of well differentiated thyroid carcinoma. The internal use of ${ }^{131} \mathrm{I}$ which is generally effective for the treatment of metastatic well differentiated thyroid carcinoma, but therapeutic gain was not at all observed. At autopsy, component of well differentiated papillary carcinoma could be seen partially in thyroid tumor. It is known that about half of the patients with anaplastic thyroid carcinoma have a previous or co-existing differentiated thyroid carcinoma. The malignant transformation of a differentiated thyroid carcinoma towards an anaplastic carcinoma is thought due to a mutation of a family of proteins, like p53.

CSF-producing neoplasms are relatively rare, and there are a few reports about CSF-producing thyroid carcinoma. In 1979, Saito et al. reported the case of thyroid carcinoma presenting marked neutrophilia and provided evidence that neutrophilia could also be caused in nude mouse which was transplanted a part of that tumor. ${ }^{4}$ Case reports of CSF-producing thyroid carcinoma with leukocytosis have been listed in Table 2. Within these reports, histological type was anaplastic carcinoma in 11 of 14 cases. $^{4-16}$ Anaplastic carcinoma might sometimes have a possibility of production of CSF. However, the case exhibiting co-production of GM-CSF, M-CSF, IL-6 was thought to be very rare, so here we reported this case. 
Table 2 Reports of colony-stimulating factor producing thyroid carcinoma

\begin{tabular}{cccccccccccccc}
\hline & Age & Sex & Histology & $\begin{array}{l}\text { WBC } \\
\text { count }\end{array}$ & Ne\% & E\% & M\% & G-CSF & GM-CSF & M-CSF & $\begin{array}{l}\text { Detection of } \\
\text { CSF }\end{array}$ & Year & Ref \\
\hline I & 7 I & F & Squamous & 26000 & 84 & $<1$ & 7 & $?$ & $?$ & $?$ & Nude mouse & 1979 & 4 \\
2 & 72 & M & Anaplastic & 20000 & 86 & 4 & 4 & $?$ & $?$ & $?$ & Progenitor cell & 1984 & 5 \\
3 & 67 & F & Squamous & 32800 & 90 & 0 & $<5$ & $?$ & $?$ & $?$ & Progenitor cell & 1986 & 6 \\
4 & 55 & M & Anaplastic & 17700 & 75 & 0 & 2 & $?$ & $?$ & $?$ & Progenitor cell & 1986 & 7 \\
5 & 59 & F & Anaplastic & 41000 & 97.5 & I & 2 & $?$ & $?$ & $?$ & Progenitor cell & 1989 & 8 \\
6 & 6 I & M & Medullary & 100000 & 2 & 96 & 0 & $?$ & $?$ & $?$ & Progenitor cell & 1989 & 9 \\
7 & 71 & F & Anaplastic & 38000 & 86 & 2 & 4 & $?$ & $?$ & $?$ & Progenitor cell & 1991 & 10 \\
8 & 61 & M & Anaplastic & 35300 & 88 & 0 & 3 & $?$ & $\uparrow$ & $?$ & Serum & 1992 & 11 \\
9 & 65 & F & Anaplastic & 85300 & 93 & 0 & 2 & $\uparrow$ & $\rightarrow$ & $?$ & Serum, IHC & 1995 & 12 \\
10 & 72 & F & Anaplastic & 36200 & 65 & 26 & 3 & $\uparrow$ & $\uparrow$ & $?$ & Serum & 1996 & 13 \\
II & 80 & F & Anaplastic & 30100 & 93 & $<7$ & $<7$ & $\uparrow$ & $\rightarrow$ & $\uparrow$ & Serum & 2000 & 14 \\
12 & 88 & F & Anaplastic & 51000 & 95 & $<5$ & $<5$ & $\rightarrow$ & $\rightarrow$ & $\uparrow$ & Serum & 2000 & 15 \\
13 & 60 & F & Anaplastic & 43200 & 85 & $?$ & $?$ & $\uparrow$ & $?$ & $?$ & Serum, IHC & 1995 & 16 \\
I4 & 73 & M & Anaplastic & 31900 & 71 & 15 & 12 & $\rightarrow$ & $\uparrow$ & $\uparrow$ & Serum & This case \\
\hline
\end{tabular}

WBC, white blood cell; Neu\%, fraction of neutrophils: Eo\%, fraction of eosinophils; Mo\%, fraction of monocyte; G-CSF, granulocyte-macrophage-colony stimulating factor; GM-CSF, granulocyte-macrophage-colony stimulating factor; M-CSF, macrophage-colony stimulating factor; CSF, colony-stimulating factor; IHC, immunohistochemical method; Ref, number of cited reference

\section{Acknowledgements}

None.

\section{Conflict of interest}

Author declares that there is no conflict of interest.

\section{References}

1. Asano S, Urabe A, Okabe T, et al. Demonstration of granulopoietic factors in the plasma of nude mice transplanted with a human lung cancer and in the tumor tissue. Blood. 1977;49(5):845-852.

2. Kasuga I, Makino S, Kiyokawa H, et al. Tumor-related leukocytosis is linked with poor prognosis in patients with lung carcinoma. Cancer. 2001;92(9):2399-2405.

3. Sherman S. Thyroid carcinoma. Lancet. 2003;361(9356):501-511.

4. Saito K, Tomotsune Y, Yamamoto K, et al. A case of primary squamous cell carcinoma of the thyroid associated with marked neutrophilia and hypercalcemia. Nippon Naika Gakkai Zassi (J Jpn Soc Intern Med). 1979;68(11):1466-1472.

5. Hirayu H, Izumi M, Sato K, et al. A case of thyroid carcinoma with marked activity of colony-stimulating factor. Horumon To Rinsyo (Clin Endocrinol). 1984;32:143-145.

6. Ishihara $\mathrm{T}$, Hino $\mathrm{M}$, Waseda $\mathrm{N}$, et al. Thyroid squamous cell carcinoma producing granulocyte-macrophage colony-stimulating factor. Horumon To Rinsyo (Clin Endocrinol). 1986;34:169-171.

7. Takaoka K, Inoue S, Fujiya S, et al. Report on a case producing colony-stimulating factor from an anaplastic carcinoma of the thyroid. Nippon Naika Gakkai Zassi (J Jpn Soc Intern Med).1986;75(1):69-74.
8. Kobayashi H, Endo K, Nishimura K, et al. A case report of thyroid papillary cancer that manifested leukocytosis and hypercalcemia after radiotherapy in bone metastasis. Gan No Rinsho. 1989;35(1):55-62.

9. Balducci L, Chapman SW, Little DD, et al. Paraneoplastic eosinophilia:report of a case with in vitro studies of hemopoiesis. Cancer. 1989;64(11):2250-2253.

10. Shima T, Yano Y, Sumida Y, et al. Colony-stimulating factor-producing undifferentiated carcinoma of the thyroid. Horumon To Rinsyo (Clin Endocrinol). 1991;39:61-64.

11. Murabe H, Akamizu T, Kubota A, et al. Anaplastic thyroid carcinoma with prominent cardiac metastasis, accompanied by a marked leukocytosis with a neutrophilia and high GM-CSF level in serum. Intern Med. 1992;31(9):1107-1111.

12. Yazawa S, Toshimori H, Nakatsuru K, et al. Thyroid anaplastic carcinoma producing granulocyte-colony-stimulating factor and parathyroid hormone-related protein. Intern Med. 1995;34(6):584-588.

13. Nakada T, Sato H, Inoue F, et al. The production of colony-stimulating factors by thyroid carcinoma is associated with marked neutrophilia and eosinophilia. Intern Med. 1996;35(10):815-820.

14. Hoshi S, Yoshizawa A, Arioka H, et al. Anaplastic thyroid carcinoma with lung metastasis producing CA 19-9 and GM-CSF. Nippon Kokyukika Gakkai Zassi. 2000;38(5):391-397.

15. Sato T, Omura M, Saito J, et al. Neutrophilia associated with anaplastic carcinoma of the thyroid: production of macrophage colony-stimulating factor (M-CSF) and interleukin-6. Thyroid. 2000;10(12):1113-1118.

16. Iwasa K, Noguchi M, Mori K, et al. Anaplastic thyroid carcinoma producing the granulocyte colony stimulating factor (G-CSF): report of a case. Surg Today. 1995;25(2):158-160. 